\title{
The Effect on Divorce of Legislated Net-Wealth Transfers
}

Douglas W. Allen*

Simon Fraser University

In recent years, legislatures have imposed several types of guidelines restricting court discretion. Guidelines designed around "average" cases, however, can lead to problems for "nonaverage" situations. In the context of divorce, poorly designed child support guidelines may create an opportunity for a netwealth transfer in excess of the costs of children for "nonaverage" families and therefore create an incentive to divorce. This incentive to divorce, when coupled with the ability to divorce under no-fault laws, may lead to higher divorce rates for certain classes of couples. This article exploits the 1997 Canada Child Support Guidelines to test the divorce prediction using data from the Survey of Labour Income Dynamics. I find separation rates increase after implementation of the Guidelines among couples with income of $\$ 25,000$ per year.

\section{Introduction}

Martha Stewart's sentencing in the summer of 2004 to 5 months in prison, 2 years probation, and a $\$ 30,000$ fine was a dramatic introduction to U.S. sentencing guidelines for many Americans. Despite the estimated 300-400 million Stewart lost from the scandal, the federal judge was constrained to impose the stiff sentence. The Stewart case points to the fundamental trade-off in the use of legislated guidelines as a substitute for court discretion. On the one hand, it is argued that discretion leads to unpredictable and inconsistent awards. On the other hand, guidelines force the same award on potentially different cases. To the extent guidelines are designed around the "average" case and to the extent guidelines are inflexible, judgments in "nonaverage" cases may be inappropriate and involve a net transfer of wealth. To the extent guidelines do lead to such transfers, there will be subsequent changes in behavior to take advantage of and/or mitigate them. This article examines a particular type of guideline - child support - and argues that when the assignments of dollars of support are out of line with the costs of children,

\footnotetext{
*Burnaby Mountain Professor of Economics, Department of Economics, Simon Fraser University. Email: allen@sfu.ca.

This research and analysis are based on SLID data from Statistics Canada, and the opinions expressed do not represent the views of Statistics Canada. Thanks to Peg Brinig, Jane Friesen, Brian Krauth, Gord Myers, and two anonymous referees for net transfers of comments.
}

The Journal of Law, Economics, \& Organization doi:10.1093/jleo/ewm013

(C) The Author 2006. Published by Oxford University Press on behalf of Yale University. All rights reserved. For permissions, please email: journals.permissions@oxfordjournals.org 
then there can be changes in divorce behavior in an attempt to capture the legislated wealth transfer.

Child support guidelines exist in both Canada and the United States. Generally speaking, the guidelines in both countries operate along the same principle of attempting to equate the standard of living between the two separated households. ${ }^{1}$ This article focuses on Canada's recent changes in child support guidelines because their design creates the opportunity for significant wealth transfers and therefore provides an opportunity to test the hypotheses of the study. Although it is necessary to delve into the mechanical construction of the Canadian guideline tables in some detail, the lessons apply generally to other jurisdictions with child support guidelines.

In Canada, prior to 1997, child support arising from family breakdown was determined at the discretion of a judge in a family law court. This system was replaced by a set of tables commonly referred to in Canada as "the Guidelines." These tables determine the amount of child support based on only two parameters: the number of children in the custodial home and the noncustodial parent's income. ${ }^{2}$ Officially the Guidelines were designed for the best interests of children in an attempt to reduce child poverty and provide more consistent awards across the country (See Canada 1995, 7). In practice, however their actual construction overcompensates for the cost of raising children for families with higher incomes. In addition, these payments are more than the discretionary amounts ordered and paid out prior to 1997. Taken together, these conditions provide an increased incentive to divorce within high-income families at the "margin of divorce" after 1997. This prediction is tested using data from a panel of individuals from 1993 to 2002. The results show that the guidelines made marriages less stable as certain incomes within the family increase.

This article makes no general argument for or against guidelines, per se. Rather, there are two broad implications of this study. First, if child support guidelines are to be successful in equating standards of living between the custodial and noncustodial homes, then care must be taken in their design to avoid large wealth transfers in excess of cost. Second, this article highlights the fundamental link between property/custody/support laws and the grounds for divorce. Since the late 1960 s, the western world has radically altered the

1. Argys and Peters (2003) report that substantial numbers of child support arrangements in the United States are cooperatively agreed upon, without resort to guidelines. They also find the amount agreed to and received is higher in the case of cooperative settlements than in courtimposed settlements. In Canada, the Guidelines are federal legislation, whereas in the United States each state separately regulates child support.

2. The Guidelines are a little more complicated than this. The amount paid depends on whether custody is shared or not, and there is an allowance for judges to depart from the Guidelines for high incomes or extraordinary expenses. Still, there is a legal presumption that the Guidelines will be followed, and in practice this almost always means they are adhered to. The federal act only applied to married individuals. However, the provinces immediately adopted the legislation to apply to other quasi-marital arrangements. Most important for the purposes of this study, the law does apply to common-law couples. 
grounds for divorce through the introduction of no-fault laws. These laws create an ability for a married individual to engage in unilateral divorce. Many studies have attempted to find a connection between no-fault laws and divorce rates - with mixed results. All these studies implicitly assume there is an underlying incentive to divorce. Yet the willingness to divorce is different from the ability to divorce. In fact, changes in divorce rates over time are likely related to changes in marital property and custody laws, which provide some of the incentives to divorce or not. Failure to recognize the interaction of property/custody/support laws with no-fault divorce laws may lead to a misinterpretation of changes in divorce rates over time. ${ }^{3}$

The article is organized as follows. The next section lays out in considerable detail the construction of the guideline tables and demonstrates the theoretical possibility of an overcompensation. Section 3 shows, in a simple model, how this creates an incentive for divorce and lays out the three main predictions of the study. Section 4 describes the data, experimental design, and results of the tests. Finally, Section 5 places these results within the context of the no-fault divorce debate.

\section{Do the Guidelines Result in an Overcompensation?}

What makes the Canadian guidelines academically interesting is that they increased child support for certain types of families relative to the amounts they would have paid prior to 1997. I demonstrate this with a two-stage argument. First, I argue that the current guidelines overestimate the cost of children based on what economists currently understand about equivalence scales. I argue that the Guidelines make three critical assumptions which all lead to an overcompensation. Second, I use what information we have regarding the earlier judicial decisions to argue that prior to 1997, courts assigned support awards that were consistent with estimated costs of children. Hence, the post-1997 awards are larger relative to the pre-1997 awards for some families.

\subsection{Three Issues in Guideline Creation}

Canada's Department of Justice (DOJ) began designing the Guidelines in 1990. In arriving at the tables, they made three critical decisions with respect to the costs of children, the sharing rule, and the value of children. These decisions systematically increased the net wealth transferred to the custodial household. This section identifies the three sources of overcompensation.

2.1.1 Estimating the Costs of Children. Canada's child support guidelines are based on a linear equivalence scale of the form: $a+b(n-2)$, where $n$ is the total number in the household, $a$ is the number necessary to make a

3. Indeed, many legal changes to these laws over the past 30 years have reduced net-wealth transfers. Thus, the Canadian guidelines are a departure from the series of family property and custody law changes that have taken place both in Canada and the United States since the adoption of no-fault divorce legislation. 


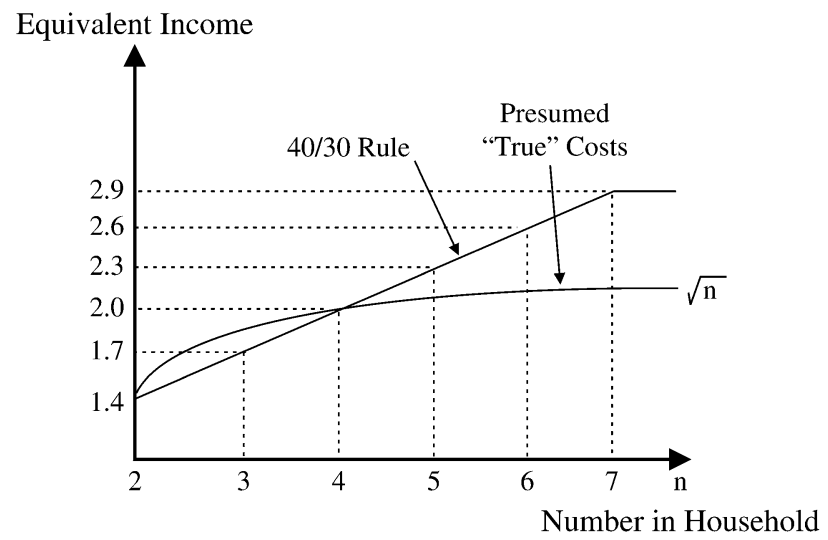

Figure 1. Equivalent Expenditures for Different Sized Households.

two-member household equivalent in terms of goods and services to a singlemember household, and $b$ is the "marginal cost" of extra members in the household. ${ }^{4}$ At the time, the DOJ had a choice of 15 scales to choose from, with values of $a$ ranging from 1.09 to $1.46 .^{5}$ In the end, it was decided to use the Statistics Canada 40/30 rule which set the value of $a=1.4$ and the value of $b=0.3$, for an equivalence formula of $1.4+0.3(n-2){ }^{6}$

The chosen equivalence scale depends on just two parameters: the number of children and income. In terms of estimating costs based on the number of children, the 40/30 rule does a reasonable job. ${ }^{7}$ Consider Figure 1 where the number of individuals living within a household is listed on the horizontal axis. Along the vertical axis is the equivalent income ratio necessary to make these households have the same equivalent income as a household of one individual.

As we can see, the 40/30 rule assumes a linear relationship between the two, up to six children. After six children, the guidelines assume that the marginal cost is zero. Economists often assume that the cost function in terms of numbers in the household is approximately equal to $\sqrt{n}$ in order to capture economies of scale. ${ }^{8}$ Figure 1 plots this function as well. For four members in the household, the 40/30 rule provides exactly the same equivalent income as the $\sqrt{n}$ cost function. For fewer members, there is a trivial difference, and even though this difference grows with increases in the size of the household, at

4. An equivalence scale is a ratio of two expenditure functions.

5. See Finnie et al. $(1995,11)$. The 1.46 value came from a study of low-income data and according to their table is "higher than a true 'equivalence,' due to an important aspect of social assistance policy." The next highest is the Statistics Canada value of 1.4. The ranges for the value of $b$ were between 0.15 and 0.4 . Thus, the DOJ picked the highest value for $a$ and one of the highest values for $b$ from their choice set.

6. This number is then multiplied by the income of a single person to arrive at the equivalent income for a given sized household.

7. The Guidelines have a built-in limit placed on six children. That is, there is no increase adjustment in payments made for more than six children.

8. For example, See Atkinson et al. (1995) for a classic reference. 
seven members the maximum difference is only $9.8 \%(0.26 / 2.64)$. Clearly no significant wealth transfer results over the number of children.

The potential net-wealth transfer involving income is much different because there is more variation in income than family size, the chance for extremely high-income levels is not uncommon, no cap similar to "more than six children" is available for income, and most important, the 40/30 rule was designed for expenditures around Canada's low-income cutoff. ${ }^{9}$ Thus, the $40 / 30$ rule can lead to serious errors in estimating the costs of children when incomes are not at the cutoff levels. Using the linear 40/30 rule in the neighborhood of the low-income cutoff will tend to yield small errors, but as you move away from the level of income used to arrive at them the magnitude of the errors increase if the $40 / 30$ rule is inappropriate. ${ }^{10}$

Consider Figure 2 where the income of a single individual is given along the horizontal axis and the equivalent income for a household of three is given along the vertical axis. The 40/30 rule generates an equivalence income function which is linear through the origin and has a slope of $1.7(=1.4+0.3)$. This means if a single household has an income of $\$ 10,000$, a three-member household would require $\$ 17,000$ to be equally well off; if the single income is $\$ 100,000$, then the triple household would require $\$ 170,000$, etc. The most recent empirical estimates of this relationship show that this type of linear relationship is false. Figure 2 shows an estimated equivalence income function based on Donaldson and Pendakur (2004). ${ }^{11}$ It shows that as we move away from moderate levels of income, the difference between the equivalent income

9. This last point needs emphasis. The 40/30 rule was devised to help Statistics Canada determine its "low-income cutoff," which is Canada's unofficial "poverty line." In calculating expenditures at these levels, Statistics Canada uses the 40/30 rule. Thus, the irony of choosing the linear 40/30 rule is that even though it was devised by Statistics Canada to study expenditures around the low-income cutoff levels, the Guidelines apply to all levels of income.

10. The Guidelines also ignore the fact that savings increase with income. Expenditures on children could be linear with the total expenditures of the household. However, as income increases, savings increase and total expenditures fall as a percentage of total income. Added to this is the "extra-expense" clause in the Guidelines. Extra expenses are shared between the parents in proportion to their relative incomes. What constitutes an extra expense has become a major source of litigation, thus defeating one of the goals of the Guidelines. The extra-expense provision amounts to double counting since the Guidelines were created based on all expenses.

11. The estimates made by Donaldson and Pendakur (2004) are complicated, but they find:

... that equivalence scales for households with children decrease significantly with expenditure. For example, the GESE-restricted equivalence scale for dual parents with one child is 1.93 at low expenditure and 1.62 at high expenditure. [2004, 4]

What this means is that the equivalence income function does not go through the origin and may not be linear. They find that for two children living in a single-parent household, the equivalence scale falls dramatically (their estimated point elasticity is -0.40 (Table 4,22 ). They go on to estimate many scales under a number of different assumptions. They also estimate these scales for average and low incomes, which means little confidence can be placed in extrapolating their numbers to large incomes. In Figure 2, I do the extrapolation for the purpose of demonstration only, the true equivalence scale at large incomes is likely much smaller than what they estimate. I also use the scale of 1.2 , which is an interpolation of one of their scales $(2004,24)$ which comes closest to the example of $n=3$ I use here. 


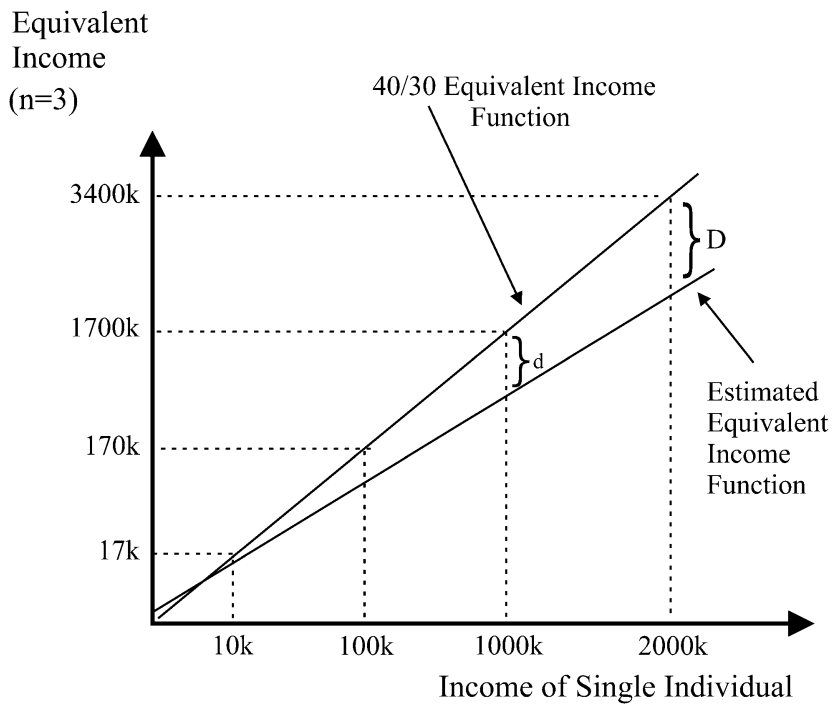

Figure 2. Equivalent Expenditures for Households of Different Incomes.

generated by the $40 / 30$ rule and the true equivalence relation starts to grow. At an income of $\$ 1,000,000$, the $40 / 30$ rule states a three-member household needs $\$ 1.7$ million, but using the Donaldson/Pendakur results suggest the estimated costs of the triple household would be $\$ 1.2$ million. The 40/30 rule, therefore, overestimates the equivalent income by $\$ 500,000 .^{12}$

2.1.2 The Choice of Apportions. The second feature of Canada's Guidelines is its particular sharing rule called the Revised Fixed Percentage. The general idea of the adopted rule was to share the postseparation costs of the child when the parent's incomes are equal and use this as the basis of a fixed percentage approach. It is useful to examine the actual formula for doing this. ${ }^{13}$ Suppose that the income of the noncustodial parent (NC) is $\$ 60,000$ and the income of the custodial parent (C) is also $\$ 60,000$ and that this couple has two children. The Revised Fixed Percentage rule assumes that the income relative to the needs of the household should be the same. This means the following equation should hold:

$\frac{\text { disposable income of } \mathrm{NC}}{\text { expenditures of } \mathrm{NC}}=\frac{\text { disposable income of } \mathrm{C}}{\text { expenditures of } \mathrm{C} \text { and children }}$.

12. For incomes over $\$ 150,000$ the guidelines do allow the courts the discretion to set the amount of child support. If we take the Donaldson and Pendakur estimates seriously, however, the 40/30 rule overestimates costs at very low incomes as the number of children increases.

13. This is found in a technical report of the Department of Justice (Canada 1997). 
The relative expenditures are simply given by the equivalence scales, so this equation is rewritten as:

$\frac{\text { disposable income of } \mathrm{NC}}{1}=\frac{\text { disposable income of C }}{1.4+0.3(n-2)}$,

where $n$ is the number of people living in the custodial household (this holds for families with up to six children). For the given incomes above this would give:

$\frac{\$ 60,000-T-\mathrm{CS}}{1}=\frac{\$ 60,000-T+\mathrm{CS}}{1.7}$,

where $T$ are the taxes paid and CS is the amount of child support. In this case, if we solve for CS, we get $\$ 15,555-0.26 T$. If we assume an average tax rate of $25 \%$, the amount of the child support award is $\$ 11,655$.

Seeing the explicit way in which the tables are calculated demonstrates a key assumption which leads to an overcompensation to the custodial parent. In equation (2), the noncustodial parent's disposable income is deflated by 1 . This assumes that a single parent has expenses identical to a single individual who is not a parent. Noncustodial parents, however, have to maintain a home where the children can stay over for weekends and vacations without having to camp out on the living room floor. This extra housing stock remains unused for much of the year but must be maintained. Likewise, whereas a single individual living in an urban setting may be able to get by without a car, the noncustodial parent may have to maintain a minivan for the children, their friends, and sporting outings. In short, it seems plausible that the noncustodial parent should have their disposable income deflated by some amount closer to the custodial parent's deflator. ${ }^{14}$ Thus we see the sharing rule itself, with its noncustodial deflator, generates a transfer to the custodial household. ${ }^{15}$

2.1.3 The Value of Children. The third major assumption that causes problems in the Guidelines relates to the treatment of children. The theoretically correct way to account for the cost of children is to begin by recognizing that children enter the utility function of their parents and then construct an expenditure function. In practice, however, this requires the comparison of unobservable utilities across individuals - an intractable task. Interestingly, the expenditure techniques to deal with this technical problem amount to

14. Ironically the Guidelines contain a $40 \%$ rule, whereby there is an adjustment to the payment if custody is shared and the children spend at least $40 \%$ of their time with the noncustodial parent. Why $40 \%$ is another one of the arbitrary rules contained in the Guidelines. Finnie (1996, 385 ) notes that ignoring the direct expenses of the custodial parent leads to inconsistent awards across households.

15. This sharing rule also assumes that all noncustodial parents who earn the same income have the capacity to pay the same award. Consideration is not given to noncustodial parents who have started a new family. 
excluding children as a valuable marital good. This assumption is also built into the Guidelines. In equation (1), only the disposable income of the custodial parent enters the right-side numerator. If children generate utility, then an inclusion for the dollar value of net utility generated should also be added, which reduces the transfer CS.

Of course, children are valuable and are valued by both parents. In fact, children may be the most valuable "asset" in a marriage or domestic relationship. ${ }^{16}$ Not only do the Guidelines ignore this fact, they consider time spent with children in the custodial home a cost. Furthermore, they consider time spent by the noncustodial parent not to be a cost, since no adjustment is made in support payments for time the children spend with the noncustodial parent. If utility is generated over children by actually spending time with them, then the custodial parent generates more utility from children than the noncustodial parent. The Guidelines make no adjustment for this, and as a result the effective net-wealth transfer to custodial parents is increased.

\subsection{Awards Prior to 1997}

The current Guidelines may provide larger amounts of support compared to estimated cost functions and what economists consider should be counted in equivalence scales. However, this is only a necessary condition for the model below to predict changes in divorce behavior. A second condition is whether or not the child support awards are large relative to what they were prior to 1997 ? Fortunately the DOJ conducted a cross-country survey of actual court child support awards over a 3-month period in 1991. ${ }^{17}$ The sample was drawn from the population of all divorces in 15 cities where a request was made for child support. The usable sample was 869 and included data on the number of children and the level of earned income of each parent. According to the Family Law Commission "An in depth examination of other potential sources of information (mainly tax databases) indicated that although this database underrepresents high-income earners, it does, overall, represent those cases that child-support formulas are intended to cover." (Canada 1995, 53).

One of the findings of this data when compared to the simulated amounts of support that would have been awarded had the Guidelines applied is that court awards quite naturally varied considerably more by location and family type. More importantly for the current study, however, was the conclusion that

On average, the simulated awards tended to be higher than current awards for families earning over $\$ 60,000$, but lower than current awards for families earning under $\$ 30,000$. Simulated awards also tended to be higher than current awards for large families but lower than current awards for small families. [Canada, 1995, 57]

16. Brinig and Allen (2000) point out that the number one factor in predicting who files for divorce (by a wide margin) is who can expect custody of the children. In a low wealth marriage, the children may be the only marital good of any significant value.

17. See Stripinis (1992) for details of the survey. 
In other words, the courts appeared to be assigning support awards along the lines of the estimated cost functions in Figures 1 and 2. Thus, we can conclude that the post-1997 support awards under the Guidelines are likely to provide too little income for the poorest families, and too much income for the wealthiest. For family incomes between $\$ 30,000$ and $\$ 60,000$ (those levels of income around the low-income cutoff), the Guidelines are likely providing appropriate amounts of child support. The evidence, when taken in its entirety, would suggest a regime change in $1997 .{ }^{18}$

\section{Incentives to Divorce}

Let $M_{i}, i=c, n c$ be the discounted stream of utility generated through marriage to a given individual. ${ }^{19} M$ will depend on the family sentiments between all the household members, relations with extended family, household production, and all the other family miscellany marriage generates. Let $S_{i}$ be the discounted stream of utility generated by the next best living arrangement. This may be living single or living in some other household formation. Let $\theta_{i}=M_{i}-S_{i}$ be the net value of a given marriage between $c$ and $n c$. If $\theta_{i}<0$ for both, then both partners would prefer a divorce, and if $\theta_{i}=0$ for both, then both partners consider the marriage to be marginal.

Clearly the value of the next best living arrangement, $S$, depends on the income available in that state, which is heavily influenced by the Guidelines. The Guidelines, through their use of the 40/30 rule, sharing formula, and nonconsideration for the value of children, effectively overcompensate the custodial household when noncustodial income is above the low-income cutoff compared to the judicial awards prior to 1997. In creating a net-wealth transfer through divorce, the Guidelines increase $S_{c}$, lower $\theta_{c}$, and create an incentive to divorce for the potential custodial parent when $\theta_{c} \simeq 0$. At the same time, the separated wealth of the noncustodial parent, $S_{n c}$, falls because of the guideline. Assuming the marriage is efficient, there would appear to be a strong incentive for the noncustodial parent to transfer wealth to the spouse during marriage to prevent a divorce. ${ }^{20}$ Thus, it appears the effect of the Guidelines on divorce is ambiguous or inconsequential.

18. This survey evidence is consistent with the stream of newspaper articles after the introduction of the Guidelines with headlines like "Top Court Grapples with High Stakes Support Case" (Toronto Star 1999) and "Child Support Laws Discriminate Against Fathers" (Financial News 2002). It is also consistent with the debate over the bill in Senate. Senator Mabel Deware stated the " . . bill drastically increases support payments by non-custodial parents - overwhelmingly, fathers - without taking into account the income of custodial parents - overwhelmingly mothers" (Toronto Star 1996).

19. Let $c$ be the spouse most likely to gain custody if divorced, and $n c$ be the spouse most likely to be noncustodial. $M_{i}$ would account for the share an individual receives of the marital goods and the separate goods consumed while married. This study implicitly assumes an efficient marriage involves shares of 50-50. See Allen (1992) for why this is the case.

20. With no-fault divorce existing marriages should be efficient; that is, $M_{c}+M_{n c}>S_{c}+S_{n c}$. If this were not the case, one party would simply leave and the other would not be able to prevent the divorce. 
However, such a Coasian conclusion is not warranted because real marriages contain significant transactions costs that often prevent such bargains from taking place. Keeping in mind that the Guidelines will effect only marginal marriages, consider what such exchanges might involve. With a divorce the custodial parent gets custody of the children and receives spousal support through the child support payment that overcompensates for the dollar expenditures of the children. The noncustodial parent may offer the same deal within the marriage, but such deals are not legal contracts and are not credible given monitoring costs within a household. ${ }^{21}$ Furthermore, such a renegotiation based on divorce threats and property transfer is likely to create badwill between the spouses and thus lower the value of the marriage leading to divorce anyway. $^{22}$

If we assume transaction costs are sufficiently high to prevent at least some of these Coasian bargains, then we can also conclude that these subsequent divorces are inefficient because they involve an involuntary wealth transfer through the use of the Guidelines. ${ }^{23}$ An inefficient divorce is one where a divorce takes place, even though the joint gains from marriage are higher than the joint gains from separation. The Guidelines may create a situation where although the marriage is efficient, $S_{c}$ may become greater than $M_{c}$. This creates the incentive for an inefficient divorce. ${ }^{24}$

Inefficient divorces are a function of income because the problems with the $40 / 30$ rule in overcompensation increases with income. ${ }^{25}$ Thus, we have the following testable predictions:

21. Allen (1992) provides another reason for why such bargaining often fails. If we assume a redistribution of shares within the marriage is observable, it is likely to create inefficient incentives within the marriage given that the spouses originally selected each other based on equilibrium shares determined in the marriage market. Thus, using the Guidelines as a threat point within marriage to increase one's share of the marital wealth is likely to cause breakdown.

22. The same Coasian objection was made in the context of no-fault divorce (Peters 1986). However, most studies have found divorce rates did increase after the introduction of no-fault divorce because many factors prevented Coasian bargaining. Some of these factors were legal, like the Guidelines (e.g., title property laws), whereas others where more related to procreation (e.g., different timing of specific fertility investments). The list is extremely long, see Allen (1998) for a discussion.

23. This raises the question: why does the noncustodial parent not seek shared custody? There are at least three answers. First, the noncustodial parent (usually the father) may be less able to maintain shared custody given their larger marketplace human capital and job market restrictions. Most male occupations are not flexible enough for shared custody. Second, the mother may not want shared custody, perhaps because she would lose the implied spousal support. A costly legal dispute and low expectation of success may prevent the father from pursuing shared custody. Third, perhaps the noncustodial parent places a lower value on the children than the custodial parent. In all cases, the Guidelines still create an incentive on the part of the custodial parent to leave inefficiently.

24. See Allen (1998) for a detailed discussion of inefficient divorces. Note this does not imply $S_{c}>S_{n c}$. Even after the Guideline transfer the noncustodial parent may have more income or utility.

25. Since the Guidelines generate a small net transfer with respect to the number of children, there should be no significant change in separation rates regarding the number of children. 
Prediction 1. Separation rates should increase after 1997 when the income of the potential noncustodial parent increases. ${ }^{26}$

Prediction 2. Separation rates should not be a function of the potential custodial parent income after 1997.

Prediction 3. There should be no change in the relationship between separation rates and income for couples without children after $1997 .^{27}$

\section{Testing the Predictions}

This study uses the Survey of Labour Income Dynamics (SLID), a Statistics Canada Panel data set used to track labor force and income details for the provincial and federal governments. The SLID is made up of three overlapping 6-year panels starting in 1993, 1996, and 1999, with 2002 being the most recently available data year. ${ }^{28}$ A great advantage of the SLID is that it accurately measures the exact income measure used to determine the child support payment: before-tax income. ${ }^{29}$ This detailed income data often comes directly from the tax records of the individuals. ${ }^{30}$ The SLID also contains the minimum necessary information on family structure and marital status to conduct the above tests. $^{31}$

For this study, individuals were selected year by year from the panel (starting with the most recent year) if they were married or living commonlaw on January 1 of that year and remained married throughout the year or if they were married or living common-law on January 1 of that year but became separated during the year. Individuals were selected only if they were married one time. ${ }^{32}$ The yearly data files were then merged, creating a survival

26. I use separation rather than divorce because common-law couples are included in the sample. I treat common-law couples and married couples as the same because the law does. In unreported regressions I find that including a dummy variable for this type of relationship does not change the qualitative results.

27. One of the referees has pointed out a prediction regarding filing behavior: among highincome households, the potential noncustodial parent should be less likely to file for divorce. Unfortunately, the SLID does not contain information on filing behavior.

28. Data from the fourth panel, which began in 2002, is not yet available.

29. The SLID also computes an hourly wage for every respondent but not for the spouse of the respondent. Running the regressions reported in Table 2 using this measure of income (and not including a measure of spouse income) yields results that are larger in terms of the test variables and statistically significant. These regressions are available from the author.

30. Individuals are interviewed in January and then again in the middle of the year for their income information. An individual may waive the second interview and allow Statistics Canada access to their tax records. I have no information on how many chose this option.

31. The SLID is not a public use data set. To use the data, a proposal is screened by the Social Sciences Research Council of Canada, a Royal Canadian Mounted Police criminal check is conducted, an oath to the Queen is sworn, and the researcher becomes a deemed employee of Statistics Canada subject to the penalties of the Statistics Act. Results are screened by Statistics Canada, and as a result, no maximums or minimums for variables are reported in this article, and the data are not available from the author.

32. Where I count a never married individual living common-law as married once. For the remainder of the article, I use "married" to describe both types of relationships. 
panel where individuals enter in at the beginning of their panel married and either drop out when they separate or stay in if they remain married. No single individual is in the data set for longer than 6 years. ${ }^{33}$

When married, both parents are "custodial" and the SLID does not contain direct information on which parent becomes the custodial parent once there is a separation. However, after separation the custodial parent can be identified as the one living with the children. I use this information in a two-step procedure to identify the potential custodial and noncustodial parents when married. Specifically, a logit regression on separated respondents is estimated where the dependent variable is 1 if they have custody. The logit coefficients are then used to estimate the probability a married individual will be custodial if a separation occurs. If this probability is greater than 0.5 , the respondent is considered the "potential custodial parent." If lower than 0.5 , the respondent is considered the "potential noncustodial parent." 34 For every respondent, his/her spouse's income is determined from the SLID. To test the predictions in this study, I use four samples: the noncustodial parents, the custodial parents, all parents, and couples without children. ${ }^{35}$

Variable definitions are reported in Table $1 .{ }^{36}$ Table 2 shows the results of three discrete time logistic regressions using three samples of parents. ${ }^{37}$

33. In such a panel there are two types of censoring: left and right side. The classic right-side censoring results from individuals still remaining married when they leave the panel. Left-side censoring results from individuals entering the panel at different stages of their marriage. The former issue is dealt with by using a discrete time logistic model, the latter with duration variables on the right-hand side. See Guo (1993) for a discussion.

34. The sample for this regression consists of all separated respondents, some of whom had custody and the remainder who did not. The actual regression results for the custody regression are ( $t$-statistics in parentheses):

Age

Education

Major income earner

Before-tax income

Spouse's before-tax income

Male

$$
\begin{gathered}
-0.022(-1.79) \\
-0.018(-1.05) \\
2.471(5.08) \\
0.008(2.90) \\
0.056(6.37) \\
-1.439(-14.97)
\end{gathered}
$$

To test for the robustness of this method, I used two other procedures for identifying custody. First I used information within the SLID on whether child support payments are received to proxy for custody and reran the above identifying regression. Second, I used samples of "major income earner" and "secondary earners" to proxy custody. In both cases, the qualitative results in both economic and statistical significance did not change.

35. The noncustodial sample is created when the SLID respondent was the noncustodial parent. Likewise, the custodial sample is created when the SLID respondent was the custodial parent. In both cases, the data contains information on the spouse.

36. Because the SLID is not a public use data file, Statistics Canada does not allow the reporting of most summary statistics. The mean of the dependent variable is reported in Table 2 .

37. The SLID is not a random sample of the Canadian population. All regressions were run using weights with insignificant changes in the coefficient estimates. The $t$-statistics, however, were much larger with the weighted sample. The reported regressions use the unweighted data. 


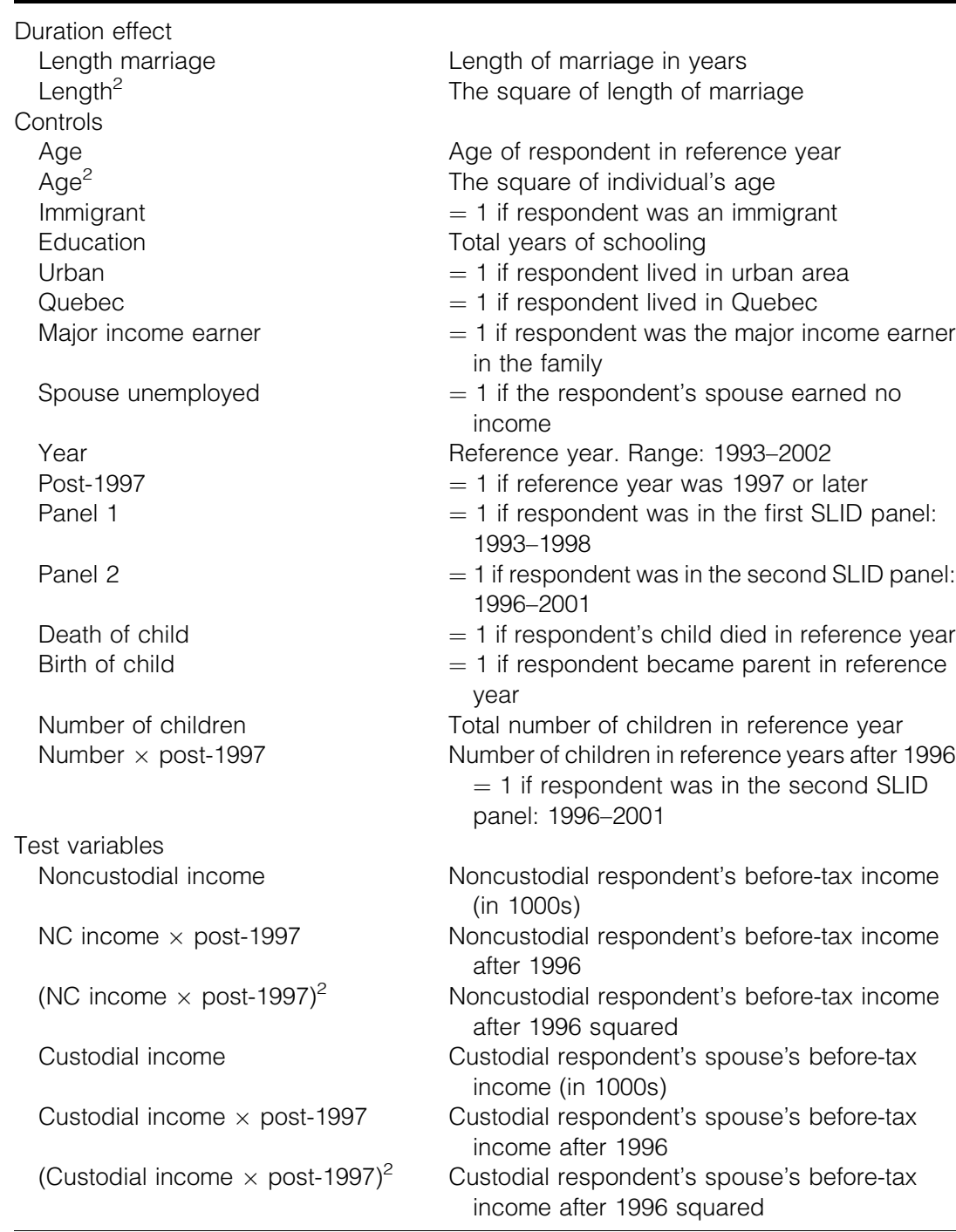

The dependent variable equals 1 if the parent separated in the reference year and is 0 if married. Table 2 shows some standard and consistent results across all three samples. Duration effects are captured by the length of marriage variables and show that the probability of separation increases with the length of marriage but at a slowly decreasing rate. Evaluated at the mean of the dependent variable, an increase of 1 year in the length of marriage increases the probability of separation by $0.33 \%$ when using regression (3)'s coefficient. A number of controls were used, and a number of consistent results show up across the three regressions: immigrants consistently have lower separation 
Table 2. Discrete Time Logistic Regressions

\begin{tabular}{|c|c|c|c|}
\hline Variable & $\begin{array}{l}\text { Noncustodial } \\
\text { sample (1) }\end{array}$ & $\begin{array}{l}\text { Custodial } \\
\text { sample (2) }\end{array}$ & $\begin{array}{l}\text { All-parent } \\
\text { sample (3) }\end{array}$ \\
\hline Constant & $-43.68(-0.57)$ & $-184.74(-2.45)$ & $-87.61(-1.66)$ \\
\hline \multicolumn{4}{|l|}{ Duration effect } \\
\hline Length marriage & $0.261(11.58)$ & $0.165(7.15)$ & $0.211(13.24)$ \\
\hline Length $^{2}$ & $-0.008(-11.64)$ & $-0.003(-4.76)$ & $-0.005(-10.91)$ \\
\hline \multicolumn{4}{|l|}{ Controls } \\
\hline Age & $0.041(0.81)$ & $0.142(2.47)$ & $0.168(4.50)$ \\
\hline $\mathrm{Age}^{2}$ & $-0.002(-2.43)$ & $-0.003(-3.47)$ & $-0.003(-6.67)$ \\
\hline Immigrant & $-0.729(-4.61)$ & $-0.795(-4.99)$ & $-0.757(-6.78)$ \\
\hline Education & $-0.049(-3.71)$ & $0.000(0.01)$ & $0.036(3.71)$ \\
\hline Urban & $0.177(1.80)$ & $0.487(4.67)$ & $0.332(4.70)$ \\
\hline Quebec & $0.254(2.37)$ & $0.263(2.33)$ & $0.202(2.66)$ \\
\hline Major income earner & $0.210(0.63)$ & $-0.322(-1.05)$ & $1.946(13.63)$ \\
\hline Spouse unemployed & $4.757(25.05)$ & $3.70(26.86)$ & $4.798(21.54)$ \\
\hline Year & $0.019(0.49)$ & $0.090(2.37)$ & $0.039(1.48)$ \\
\hline Post-1997 & $-0.513(-1.87)$ & $-0.524(-2.07)$ & $-0.265(-1.63)$ \\
\hline Panel 1 & $-0.169(-0.96)$ & $0.023(0.13)$ & $-0.103(-0.82)$ \\
\hline Panel 2 & $-0.165(-1.29)$ & $0.040(0.32)$ & $-0.055(-0.62)$ \\
\hline Number of children & $-0.597(-4.64)$ & $-0.247(-2.64)$ & $-0.373(-5.19)$ \\
\hline Number $\times$ post-1997 & $0.229(2.08)$ & $-0.019(-0.21)$ & $0.061(0.95)$ \\
\hline Death of child & $0.416(0.32)$ & $1.144(0.80)$ & $0.431(0.41)$ \\
\hline Birth of child & $-0.621(-1.53)$ & $-0.613(-1.99)$ & $-0.616(-2.54)$ \\
\hline Living with children & $0.284(1.41)$ & $0.552(3.45)$ & $0.334(2.75)$ \\
\hline \multicolumn{4}{|l|}{ Test Variables } \\
\hline Noncustodial income & $-0.017(-4.66)$ & $-0.097(-10.40)$ & $-0.032(-10.49)$ \\
\hline NC income $\times$ post-1997 & $0.028(3.40)$ & $0.020(2.36)$ & $0.007(2.26)$ \\
\hline$(\mathrm{NC} \text { income } \times \text { post-1997) })^{2}$ & $0.0005(3.85)$ & $0.001(9.25)$ & $0.001(3.89)$ \\
\hline Custodial income & $-0.045(-2.70)$ & $-0.012(-2.60)$ & $-0.013(-3.49)$ \\
\hline $\begin{array}{l}\text { Custodial income } \times \text { post- } \\
1997\end{array}$ & $-0.035(-1.61)$ & $0.008(1.10)$ & $0.003(0.62)$ \\
\hline $\begin{array}{l}\text { (Custodial income } \times \text { post- } \\
\text { 1997) }\end{array}$ & $0.001(1.96)$ & $0.000(1.46)$ & $0.000(1.16)$ \\
\hline$\chi^{2}(\mathrm{df})$ & 5320.07 (26) & $6649.97(26)$ & $11627.77(26)$ \\
\hline Percent correct & 98.9 & 98.9 & 98.9 \\
\hline$N$ & 58,255 & 68,446 & 126,701 \\
\hline Mean of dependent variable & .0161 & 0.0156 & .0158 \\
\hline
\end{tabular}

Dependent variable $=1$ if separated in reference year. $t$-statistics in parentheses.

rates, as do couples with more children; respondents living in urban centers or Quebec have higher separation rates. Most notable is the large impact an unemployed spouse has on separation rates. ${ }^{38}$

The variables relevant for this study are under the heading test variables. Prediction 1 states that the child support guidelines made higher noncustodial

38. I ran these regressions with a number of control variables, but dropped those which were economically and statistically zero. Notable among these variables was "empty nester." I could find no effect of children leaving home on the separation probability. 
income marriages less stable after 1997. In other words, the predicted sign on the variables $\mathrm{NC}$ income $\times$ post-1997 and $\left(\mathrm{NC}\right.$ income $\times$ post-1997) ${ }^{2}$ are positive. Prediction 2 states that the guidelines should have no impact on the stability of marriages when custodial income changes. Thus, the variables custodial income $\times$ post-1997 and (custodial income $\times$ POST-1997) ${ }^{2}$ are predicted to be insignificant. These two predictions hold up across all three regressions.

The results from Table 2 are quite striking. Regression (3) contains all respondents to the SLID which satisfy the selection criteria, and I will focus my discussion on this regression. ${ }^{39}$ Across the three samples, income is stabilizing to a marriage, and this is shown by the negative coefficients on both noncustodial income and custodial income. The marginal effect of the guidelines through income, however, is destabilizing. Consistent with prediction 1, separation probabilities increase with noncustodial income after 1997. Consistent with prediction 2 , the separation probabilities are unaffected by changes to custodial income after 1997. At first glance, the coefficients appear small; however, for large changes in income, the squared income term starts to dominate. For example, evaluating at the mean of the dependent variable in regression (3), the total effect on the probability of separation for a change in income of $\$ 10,000, \$ 30,000, \$ 50,000$, and $\$ 100,000$, is $-0.24 \%, 0.22 \%, 1.95 \%$, and $11.80 \%$, respectively. ${ }^{40}$ For the full sample, changes in income stabilize the marriage in total until just over $\$ 25,000$, after which the marginal destabilization caused by the guidelines starts to dominate. Changes of income over $\$ 100,000$ per year start to have very large impacts on the probability of separation. $^{41}$ Thus, the apparently small coefficients have significant impacts at income differences that are very common.

Prediction 3 noted that the guidelines should have no impact on couples without children. ${ }^{42}$ Table 3 uses a sample of respondents who do not have

39. In fact, this is the regression of interest since every divorced marriage has a custodial and noncustodial parent (in this sample). The first two regressions are reported simply to show that the results do not change based on which type of parent was the respondent to the SLID survey.

40. On the other hand, using the estimates from the custodial sample for changes in the total probability of separation when income of the noncustodial parent changes by these amounts leads to $-1.03 \%,-2.01 \%,-2.15 \%$, and $3.20 \%$. In this sample the marginal effect caused by the guidelines does not wash out the direct effect until approximately a change of income around $\$ 78,000$. One has to be cautious in considering the total effect for changes in income greater than $\$ 100,000$ given that there are relatively fewer sample points at these incomes and the standard errors increase. Rather than using a quadratic income term, I replaced it with dummy variables for income ranges: less than $\$ 25,000 ; \$ 25,000-\$ 50,000 ; \$ 50,000-\$ 75,000$; and greater than $\$ 75,000$. The qualitative results were the same: statistically significant negative coefficients for the lowest income category and large significant positive coefficients for the highest category.

41. These results are consistent with another implication from Figure 2 that I have not emphasized: the Guidelines likely undercompensate for the cost of children at very low levels of income, thus causing these marriages to be more stable. The irony is that these couples, who may have difficulty divorcing because the legal costs of divorce are high relative to their low incomes, were the very couples easy no-fault divorce was intended to help.

42. Although not tested here, presumably the Guidelines could influence the fertility rates of these couples. 
Table 3. Discrete Time Logistic Regressions

\begin{tabular}{|c|c|}
\hline Variable & Nonparent sample \\
\hline Constant & $-38.28(-0.50)$ \\
\hline \multicolumn{2}{|l|}{ Duration effect } \\
\hline Length marriage & $0.204(10.06)$ \\
\hline Length ${ }^{2}$ & $-0.005(-8.38)$ \\
\hline \multicolumn{2}{|l|}{ Controls } \\
\hline Age & $0.259(5.41)$ \\
\hline$(\mathrm{Age})^{2}$ & $-0.004(-7.27)$ \\
\hline Immigrant & $-0.912(-5.77)$ \\
\hline Education & $0.039(2.85)$ \\
\hline Urban & $0.349(3.40)$ \\
\hline Quebec & $0.187(1.69)$ \\
\hline Major income earner & $0.158(0.43)$ \\
\hline Spouse unemployed & 5.637 (14.09) \\
\hline Year & $0.014(0.37)$ \\
\hline Post-1997 & $-0.225(-0.98)$ \\
\hline Panel 1 & $-0.442(-2.47)$ \\
\hline Panel 2 & $-0.284(-2.21)$ \\
\hline Number of children & $-0.247(-2.64)$ \\
\hline Number $\times$ post-1997 & $-0.019(-0.21)$ \\
\hline Death of child & $1.144(0.80)$ \\
\hline Birth of child & $-0.613(-1.99)$ \\
\hline \multicolumn{2}{|l|}{ Test variables } \\
\hline Before-tax income & $-0.013(-3.53)$ \\
\hline Income $\times$ post- 1997 & $0.000(0.00)$ \\
\hline$(\text { Income } \times \text { Post-1997) })^{2}$ & $0.000(0.41)$ \\
\hline Spouse before-tax income & $0.000(0.00)$ \\
\hline Spouse income $\times$ post- 1997 & $0.006(0.19)$ \\
\hline (Spouse income $\times$ post- 1997 ) & $0.000(0.27)$ \\
\hline$\chi^{2}(\mathrm{df})$ & $4954.70(20)$ \\
\hline Percent correct & 96.7 \\
\hline$N$ & 20,993 \\
\hline Mean of dependent variable & .0513 \\
\hline
\end{tabular}

Dependent variable $=1$ if separated in reference year. $t$-statistics in parentheses.

children and who therefore should have separation rates independent of the Guidelines. As the results show, separation rates are not a function of post1997 income in this sample. Thus, all the regressions from the two tables provide evidence that the guidelines increased the separation rates for a particular type of family: those families with children and high primary income earners. ${ }^{43}$

43. As mentioned above, the Guidelines are also a function of the number of children in the custodial household. As mentioned in Section 2, the table amounts were adjusted so that they mimic fairly well a cost function that demonstrates economies of scale within the household. As a result, it is unlikely net-wealth transfers arise over the number of children. Table 2 indicates that though children tend to stabilize marriages, the marginal effect measured by the coefficient "number $\times$ post- 1997 " is usually insignificant, consistent with the view that no net-wealth transfer takes place on this margin. 


\section{Conclusion}

Quite often when it comes to empirical work on family issues, the variables of interest are ambiguous (e.g., what constitutes "no-fault" divorce), they are unobservable (e.g., who actually instigated a divorce), or there is tremendous measurement error in the data (e.g., contributions to the marriage). Canada's child support guidelines offer a case where these problems are eliminated. The discrete change in a federal law over the actual dollars transferred is unambiguous. The actual separation and the level of income are observable. And the SLID contains the exact income tax variables used to generate the payments. In this particular example of the effect of legal regimes on family behavior, we can have more confidence than is often the case.

This study has shown that legislated net-wealth transfers lead to predictable changes in separation behavior. Families where the potential noncustodial parent earns a high level of income became more likely to separate after the introduction of the guideline tables. The results, however, draw attention to an important implication for divorce rate studies, which continue to struggle to show a consistent effect of no-fault divorce laws on divorce rates. ${ }^{44}$ The lesson here is that, to study the effect of no-fault divorce laws on divorce rates, one must consider the entire marital law regime surrounding the divorce decision. ${ }^{45}$ Unilateral divorce, by itself, is unlikely to have a significant effect on its own since it only allows the opportunity to leave without a mutual agreement. Unilateral divorce in a jurisdiction with exploitable property/support laws, on the other hand, should have a large bearing on divorce rates. Hence, this study shows that an improperly designed set of child support guidelines that created an opportunity to transfer wealth through divorce actually increased some divorce rates substantially. Other laws which mitigate wealth transfers can lower divorce rates, and thus, reductions in divorce rates over time may simply be the result of well-designed net-wealth transferring laws which occurred over time.

As mentioned in the opening remarks, legislated guidelines are momentarily popular as a method of achieving "fair" judicial outcomes in many areas, from criminal sentences to child and spousal support. This study shows it is important to recognize that their use may be nonneutral if they create serious wealth transfers and if the rules are relatively inflexible. The purpose of this study is not to argue that court discretion is better than guidelines - discretion has costs as well. Rather it is to argue two points. First, child support guidelines should be designed to avoid wealth transfers in order to minimize the impact on divorce. Second, the ability to achieve a wealth transfer with something like child support laws is what generates increased divorce rates under no-fault divorce laws. Studies of no-fault laws should carefully consider the interaction

44. See Wolfers (forthcoming) for a recent discussion. He finds only a temporary effect of the law.

45. A good example of this is Brinig and Buckley (1998) where they define "no-fault" based on how much it costs to divorce in terms of property and custody, not just in terms of the unilateral character. 
of property and custody laws with no-fault divorce laws on separation rates, not just the no-fault provision alone.

\section{References}

Allen, D.W. 1992. "What Does She See in Him: The Effect of Sharing on the Choice of Spouse," 30 Economic Inquiry 57-67.

. 1998. "No-Fault Divorce in Canada: Its Cause and Effect," 37 Journal of Economic Behavior \& Organization 129-49.

Argys, L.M., and H.E. Peters. 2003. "Can Adequate Child Support Be Legislated? Responses to Guidelines and Enforcement," 41 Economic Inquiry 463-79.

Atkinson, A., L. Rainwater, and T. Smeeding. 1995. Income Distribution in OECD Countries: Evidence from the Luxembourg Income Study. Paris, France: OECD Publications.

Brinig, M., and D.W. Allen. 2000. "These Boots Are Made for Walking: Why Most Divorce Filers Are Women," 2 American Law and Economics Review 126-69.

Brinig, M., and F.H. Buckley. 1998. "No-Fault Laws and At-Fault People," 16 International Journal of Law and Economics 325-40.

Canada. 1995. Summary: Federal/Provincial/Territorial Family Law Committee's Report and Recommendations on Child Support. Ottawa, Canada: Department of Justice, JUS-P-673E.

- 1997. Formula for the Table of Amounts Contained in the Federal Child Support Guidelines: A Technical Report. Ottawa, Canada: Department of Justice, CSR-1997-1E.

Donaldson, D., and K. Pendakur. 2004. "Equivalent-Expenditure Functions and Expenditure Dependent Equivalent Scales," 88 Journal of Public Economics 175-208.

Financial News. 2002. Child Support Laws Discriminate Against Fathers. December 24.

Finnie, R. 1996. "The Government's Proposed Child-Support Guidelines," 18 Reports of Family Law 382-92.

Finnie, R., C. Giliberti, and D. Stripinis. 1995. An Overview of the Research Program to Develop a Canadian Child Support Formula. Ottawa, Canada: Supply and Services Canada.

Guo, G. 1993. "Event History Analysis for Left-Truncated Data," 23 Sociological Methodology $217-43$.

Peters, H. Elizabeth. 1986. "Marriage and Divorce: Informational Constraints and Private Contracting," 76 American Economic Review 437-54.

Stripinis, D. 1992. Report on the Creation of the Child Support Database. Ottawa, Canada: Department of Justice.

Toronto Star. 1996. New Child Support Law Stalled in Senate. December 14, A14. 1999. Top Court Grapples with High-Stakes Support Case. April 28, A1.

Wolfers, J. "Did Unilateral Divorce Laws Raise Divorce Rates? A Reconciliation and New Results," American Economic Review (forthcoming). 